\title{
Discussion on the Modernity Crisis of Education and Thinking Mode Transformation
}

\author{
Jiaming Zhong \\ School of Economics and Management \\ Xiangnan University, \\ Chenzhou 423000, China \\ jmzhongcn@163.com
}

\begin{abstract}
The cause of education modernity crisis lies in Descartes's subject-object dual opposite thinking mode, showing that the aim at material gains of education leading to value rationality loss, scientific world hegemony and life marginalization. Besides, the inculcation as well as controlled ability as education leads to the subjectivity alienation. This paper holds the idea that the effective way to solve education modernity crisis is to implement the education thinking mode transformation and adopts the complex thinking mode to replace the simple thinking mode.
\end{abstract}

Keywords-education; subjectivity; modernity crisis; thinking mode; complex thinking mode

\section{INTRODUCTION}

French educator Rousseau said that education maybe the primary one among those humanity causes which are beneficial to human beings [1]. Because education is the primary point to build an individual [2]. What's more, mensch will inevitably go through the education period to be a person. As social practice activities cultivating human beings, education should take the ultimate goal of cultivating people's minds with pursuing life meaning and value as the orientation. However, judging from the recent 400 years, modern education under entity based simple thinking mode has truly contributed a lot to the modern society development yet also leads to a glittering array of industrial symptoms: the tool rationality of education takes place of its value rationality; its rationality replaces its spirituality; its hegemony replaces the vivid world; moral education makes place for scientific knowledge education. All these symptoms of modern education finally lead to morality and subjectivity loss as well as mental decline, which drift away from its real meaning.

\author{
Naizhu Huang * \\ Institute of Higher Education Research \\ Xiangnan University, \\ Chenzhou 423000, China \\ xnxyhnzh@163.com \\ * Corresponding Author
}

\section{CONCRETE PERFORMANCES OF EDUCATION MODERNITY CRISIS}

\section{A. Utilitarian education leading to value rationality loss}

In recent years, the enlightenment campaign established the principle of rationality and subjectivity, which were developed by the subjective philosophy of Kant as well as the absolute reason of Hegel, which become the new god of human beings in the course of conquering nature. Besides, it profoundly affects the education throughout the world, and human beings under such environment possess instrumental rationality and lack value-caring, they can only become rational yet inhuman experts. Elliot reveals the facts concerning the utilitarian ideas of modern people: individuals demand more education not for wisdom but for sustaining their life; the states require more education in order to exceed other countries; a class requires more education to surpass other classes or at least not worse than other classes; therefore, education is associated with the technical effectiveness on the one hand, and on the other hand, it is related to the status enhancement. If education cannot bring along with more money, greater power to control people, higher social status or at least a steady and respectable job, then there should be few people willing to be engaged in education[3]. In $20^{\text {th }}$ century, two world wars broke out along with frequent regional wars and conflicts, destruction of human nature, deterioration of the environment and natural disasters, which turn the rationality from positive to negative, becoming the power of ruling and imprisoning people and getting into trouble. Obviously, scientific rationality brings along with material wealth yet cannot establish an ideal world, 'the historical trace of modernity is going through a period from liberation to self-enslavement [4]'. From the perspective of Husserl, a Phenomenology master, the crisis of European science is fundamentally 
lies in the human being crisis, 'people only recognize science only admit facts[5]'. Life does no longer possess humanity, meaning yet becomes a machine without emotion and humanity. So how does the crisis come out? Husserl believes that it does not lie in the rationality itself because it is comprehensive. The crisis lies in its external forms, namely, it insistently advocates naturalism and objectivism and therefore rationality becomes single empirical, scientific and tool rationality. Even though, western countries always adhere to rationalism, the human rationality and value rationality are completely divorced in the later period of 19th century. Nowadays, people are controlled by empirical science and are satisfied with the so-called prosperity created by it. Such unique phenomenon means that modern people causally wipe out a vital problem for real people, which is exploring whether the entire life is meaningful or not.

\section{B. Education world: The hegemony of scientific world and marginalization of living world}

The philosophy in modern western countries highly holds the banner of rationality. Yet, when human beings are conquering nature and creating material wealth, they suffer from spiritual anguish. People who live in the world ought to lead rich, free and complex lives. Besides, they create organizations have orderly life with original yet comprehensive personalities. However, this world, which ought to be paid attention to is replaced by the world created by Galileo's mathematical methods and his successors, the physicists in recent years admitted this replacement. The world, which really exists and is felt through perception as well as experience is gradually forgotten by people in the course of constructing scientific world.

Education stems from people's daily needs, the original education is naturally integrated with life and life is the natural field for education. However, with the emergence of institutional education, the educational activities become more and more complex which separate from life as an independent form: the unique education world. The education world comes from the living world of children. However, under the governance of scientific rationality, the scientific world is dominant and education becomes rational one, as well as cavernous character memory, demonstrating a trend pursuing scientific doctrine and book knowledge on the one hand; on the other hand, education activities and management are controlled by scientific rationality and schools as well as institutions become political and economic organizations, pursuing efficiency and external management, which can be beckons as the performance of colonization of Life-world concluded by Habermas, showing in the prevalence of bureaucratic autocracy and bureaucracy. That is to say people who are managed are objects identified by bureaucrats without love and hate. Judging from the work of manage people, it does not need emotion but has to manage them like objects[6]. Colonization of the educational life makes a dominating-dominated relationship between teachers and students as well as supervisors and managers. Under the governance of scientific rationality, the life of children is divided into two worlds which are not related with each other: the daily life and education life. In the education world, children act like puppets who are divorced from the real world. In daily life, children obtain satisfaction by violating education activities. The former makes the education becomes meaningless because education implementation is for scores and people receive education for being enrolled. As a result, people gradually lose life interests and find education miserable. The latter makes life be meaningful and the life becomes primitive jungle without education guidance. Therefore, the break of education and life reflects that the scientific world forgets the life world.

\section{Epistemology of positivism and inculcation of education}

Positivism in the $19^{\text {th }}$ century denied ultimate knowledge, which takes the world as objects based on empirical research methods in order to have a knowledge of the world nature. The positivism has the following features: firstly, such knowledge has disenchantment characteristic, which is empirical. Any conceivable scientific statements cannot be denied or proved by perceptual experience are meaningless and cannot be recognized and those can be denied or proved by perceptual experience are meaningful and can be recognized [7]. In addition, the epistemology of positivism is the one in accordance with theory of knowledge, believing that knowledge is determined by the nature of things and if it conforms to the objective it is correct or it is incorrect. Besides, the empirical knowledge is objective, universal and neutral which asks people to get rid of their own opinions, understandings, experience, emotion and common senses etc. Concerning knowledge, people cannot understand but take it as external matters.

The epistemology of positivism believes that the teaching process is a process of understanding based on indirect experience and is different from the process of understanding in daily life as well as the one in researching. The only task in the course of teaching is to recognize the indirect experience. Knowledge is objective, universal and neutral which won't change because of experience of researchers. Therefore, the aim of education is to help students master the nature of things and acquire objective knowledge of matters. The task of teachers is to help students understand the objective, universal and neutral knowledge. The relation between educators and students is accepting-receiving knowledge. Class teaching has become an effective teaching form to impart knowledge; lecture and discussion are also effective approaches to impart 
knowledge and experiment method as well as demonstration method lose the exploring connotation while becoming forms to test knowledge, help to memorize and understand knowledge; besides, the theory practice principle, intuitive principle, consolidation principle and step by step principle all serve the purpose to imbue the knowledge. Teaching evaluation checks students' memory, understanding, judgment of knowledge and the simple application. The epistemology of positivism does not only kill the meaning of life but also the spiritual life of students. Teaching completely becomes an external activity, aiming to master objective knowledge. In this case, children only passively absorb knowledge. Even when the dominant position of students as well as their enthusiasm are emphasized, they are still passive while learning.

Such education without vital force is concluded as banking education by Paulo Freire, a Brazil educator. He said that education becomes a behavior of storage. Students are custodians, while teachers are the depositors. Teachers do not communicate but publish reports so as to let students patiently accept, memorize and storage the teaching materials. As a result, such education only makes students accept and store knowledge. In such banking education, people who think they are knowledgeable hold the idea that knowledge is a kind of charity for ignorant people. They beckon that others are absolutely ignorant, which is a kind of oppression, and denies that education as well as knowledge is a process of exploring [8].

\section{D. controllable education and subjectivity alienation}

The first principle of Descartes's Cogito Ergo Sum lays the foundation and tone of western subjectivity. The subjectivity shows the ego idea while there is a relation between subject and object, which highlights subject conquering objects and puts the willingness and power of subject to object so as to take advantage of object. American scholar F.R.Dallmayr summarizes three characteristics of modern subjectivity: firstly, it is a kind of anthropocentrism taking the objective of ruling nature; secondly, it is a kind of egocentric possessive individualism; thirdly, it is individual subjectivity which excludes intersubjectivity [9]. The subjectivity established based on subject-object dichotomy will inevitably legalize the confrontation and separation between human and nature, human and society, human and others, human and themselves which shall lead to infinite pillage of nature and ecological crisis as well as the emergence of nationalism and power politics, discrimination, wars, intrigues and credit crisis etc. While pursuing the subjectivity, people also go against it and while pursuing freedom, they are also imprisoned. Just like Manfred Frank says, since the beginning of the Enlightenment, the subjectivity of human being has been given the supreme status by spiritual science. One of the outstanding achievements of the enlightenment is the development and promotion of subjectivity. However, more than 200 years social situations and human practice improve that real subjectivity does not exist, which has always been ruled [10]. The subjectivity of human beings is a modern concept, which reflects selfemancipation and the pursuit of freedom and is inevitable for people to get rid of the attachment relationship. The crisis of subjectivity does not lie in its errors but in its incorrect understanding. Therefore, the subjectivity cannot be denied, but people's subject consciousness should be changed. .

The subjectivity of modern education is actually the one in guest and host relationship which only recognizes one subject that is educators, and students are objects in the course of education. The relationship between them is not acquaintanceship but object relationship. Acquaintanceship is equal which respects the subject and subject with dialogue, communication so as to reach an agreement. Yet, object relationship is the one between subject and object, which refers to the condition that the subject puts its aims, consciousness, ability and power into object so as to shape it, trying the utmost to reflect the willingness of subject and change the object. Therefore, it can be called a target-means relationship. The modern education does not pay attention to the expression of life, which is rooted in the condition that in subject-object relationship, students are regarded as the objects. Students are created as the objects based on the willingness of subjects and the course of education is a process of training and controlling. To conclude, the relationship between educators and students is controlling-controlled as well as oppressing-oppressed one. In such relation, human beings are regarded as objects without life and are completely controlled, lacking of a basic nature-freedom. In order to rule common people, controllers try unremitting efforts to give up people's desire to explore and discourage their spiritual life as well as creative ability, which are the characteristics of life.

\section{THE PHILOSOPHICAL BASIS TO SOLVE MODERNITY} CRISIS OF EDUCATION IS TO CHANGE THE THINKING MODE

\section{A. Practical and simple thinking mode is the root}

\section{causing education symptoms}

Practical and simple thinking mode is dualism of subject and object and when being asked what is the nature of education, education is the subject and object and 'what' is the nature so as to isolate the education from its background and put the education in the environment without time, space and social environment and forget the relationship between education and environment. This way presets the condition for people to find the nature of education and ignore its historical as well as social features. As a result, the concrete and complicated situations of education are ignored and 
cognition of education based on this is not comprehensive. In other words, adopting simple and practical thinking mode to explore the nature of education cannot obtain its full and comprehensive recognition. Education without space, region, class, sex, nation as well as historical, social, cultural and regional features only seeks hegemony. In addition, the practical feature puts education in troubles with a dazzling array of conflicts as well as contradictions. The subjectivity recognition of education makes people neglect its real entity and for a correct recognition, people should try to achieve the re-enchantment. However, the subjectivity of modern education is in accordance with the development of modern science and technology and will definitely get intro trouble. Therefore, people have to abandon the practical and simple thinking mode so as to seek the teaching reform approach of Archimedean point from the perspective of education philosophy as well as complex science. Based on this, breakthroughs can be achieved. In the author's opinion, the Archimedean point is the reform means to change the thinking mode, which is the fundamental problem of implementing education reform.

In the field of education, philosophy rather than science is the important or fundamental factor affecting education. In another word, it is philosophy that finally determining education. A famous educational philosopher, Jorge Naylor once said most of the common education problems can be finally explained by philosophy [11]. Shermis also said that the nature of science is to find unknown and aims which seeks the truth and focuses on the point of understanding nature, life, society and individual development, trying to correctly elaborate the rules and condition of things [12]. In the contrast, philosophy is different because to some extent, it explores the meaning of life and even the world at large. It contains a value system with targets, wiliness, interest, appreciation etc, which does not pay attention to what the world is without seeking the truth of the world but makes people understand how to carry out practice and understand the world with logic.

\section{B. From simple thinking mode to complex thinking \\ mode: the fundamental thinking mode of modern education reform}

Philosopher Wittgenstein once said, deeply grasp the difficulty is difficult because superficial solution cannot fundamentally change the problem. Only by deep understanding can people think about matters with a new thinking mode. The new thinking mode is the most difficult one. Once there is a new thinking mode, the old problems will disappear; in fact, these problems are no longer problems[13]. Engels said, people cannot achieve truth without correct thinking mode if people start from one-sided prerequisite[14].

Modern education aims to educate human beings who are complicated. Just like Edgar Morin once said, human beings are universal. It should also be seen that even though they are imprisoned in common life, they are unique can create a universe because human beings have inner multiplicity and various imagined characters and they are always exploring the unknown. Everyone has his dreams and imaginary galaxy with desire and love remaining to be satisfied. Unfortunate life, endless anguish make them live through the world[15]. Education system is more complicated than human beings and its components include school (school management, school culture, surrounding environment, facilities, management level, relation with local administration departments, government intervention etc), students (understanding of life and society, experience, relationship with other students, relationship between students and parents as well as teachers), the world behind students (national education policy, the education level of parents, family education level, family income, relationship between parents, political, economic and scientific factors), teachers (professional quality, education philosophy, personal character, mental condition, income, mental pressure, relation among teachers, relationship between teachers and headmasters), courses and teaching methods etc. Concerning the complex education system, which scientific conclusion shall be summarize with simple and practical thinking mode? So, the key to change the modern education is to develop a new thinking mode which can replace it so as to fundamentally solve various problems and reveal the demerits of modern education.

The complex philosophy which has been developed rapidly in these years is an ideological weapon for us to solve modernity crisis of education. While talking about complexity thinking, ancient Greece philosophers once supposed the process from chaos to order, Descartes metaphysically put forward the idea of Vortex evolution model, Spencer philosophically put forward that the people grow with complex structure, Bergson came up with the idea of complexity evolutionary as well as creativity and Poincare concluded the nonlinear conclusion based on researching on three-body problems. In the middle of $20^{\text {th }}$ century, complex problems were highlighted. The general system, cybernetics and information theory, synergistic theory, hypercycle theory and catastrophe theory created by Bertalanffy, Wiener, and Shannon etc. are bases for complex science development, the dissipative structure theory established by Prigogine, Haken, Tom, and Eigen are thought of pioneers, while the chaos theory and fractal theory are dominant. The emergence of complex science remarks the fundamental reform of philosophy thinking mode, which is a breakthrough for mechanistic, reductionism, unadorned realism of Newton. As an emerging course, it has powerful vitality and almost all of things throughout the world can be explained by it except for few simple physical systems. Education, as complex system should be studied by this complex thinking mode. In China, 
Yang Zhongkai etc. once carried out comparison research on the simple thinking mode and the complex thinking mode[16], which has heuristic meanings to research on the education problems. The researcher results are shown in Table 1.

TABLE I. THE COMPARISON BETWEEN SIMPLE THINKING MODE AND COMPLEX THINKING MODE

\begin{tabular}{|c|c|c|}
\hline & Simple thinking mode & Complex thinking mode \\
\hline $\begin{array}{l}\text { Views toward } \\
\text { things }\end{array}$ & $\begin{array}{l}\text { Everything is a part of the } \\
\text { collection, and the essence of things } \\
\text { does not lie in its whole, but its } \\
\text { parts. }\end{array}$ & $\begin{array}{l}\text { Everything is organic system, which has } \\
\text { new quality in isolation. }\end{array}$ \\
\hline $\begin{array}{l}\text { Views toward } \\
\text { component } \\
\text { relationship }\end{array}$ & $\begin{array}{l}\text { Components have simple linear } \\
\text { lationship which can be studies } \\
\text { hile cutting relationship. }\end{array}$ & $\begin{array}{l}\text { ear relationship so } \\
\text { between integrity }\end{array}$ \\
\hline $\begin{array}{l}\text { Views toward } \\
\text { cause and effect }\end{array}$ & $\begin{array}{l}\text { Things change based on the } \\
\text { mechanical law of causation, } \\
\text { namely one cause must determine } \\
\text { one result which inevitably affect } \\
\text { next result and the original cause is } \\
\text { the first push without chances in the } \\
\text { course. }\end{array}$ & $\begin{array}{l}\text { In the overall process of change, things } \\
\text { obey the cause and effect feedback rule and } \\
\text { different results could lead to same result and } \\
\text { different results may have same cause. The } \\
\text { system is able to change the chaos into order } \\
\text { and is able to integrate chance and necessity. }\end{array}$ \\
\hline $\begin{array}{l}\text { Whether the } \\
\text { movement is } \\
\text { reversible }\end{array}$ & $\begin{array}{l}\text { The movement process is } \\
\text { reversible without the arrow of time } \\
\text { and the inversion of motion } \\
\text { equation on time is bilateral and } \\
\text { therefore there is not an evolution } \\
\text { process. }\end{array}$ & $\begin{array}{l}\text { Time is associated with irreversible } \\
\text { movement, so everything has its development } \\
\text { process of evolution, and people must use } \\
\text { rational ideas to regard time as the } \\
\text { measurement for evolution of the material } \\
\text { world. }\end{array}$ \\
\hline $\begin{array}{l}\quad \text { Views toward } \\
\text { global } \\
\text { optimization }\end{array}$ & $\begin{array}{l}\text { If the parts are good, it is good. } \\
\text { It adopts an evaluation method from } \\
\text { smallest to total. }\end{array}$ & $\begin{array}{l}\text { Local optimum obeys total optimum and } \\
\text { sometimes we can sacrifice local optimum so as } \\
\text { to ensure the total. People start from the whole } \\
\text { to deeply explore the parts and finally return to } \\
\text { the whole. }\end{array}$ \\
\hline
\end{tabular}

\section{ACKNOWLEDGMENT}

This study is supported by the construct program of the key discipline in human province, Hunan Province 2013 ordinary university Teaching Reform Project(Xiang Jiao Tong[2013]223 -447),China.

\section{REFERENCES}

[1] Rousseau, translated by Li Pingou. "Emile or on education". Beijing:People's Education Press, 2001,pp2.

[2] Comenius, translated by Ren Gan. "Great Didactic". Beijing:People's Education Press, 1979,pp35.

[3] T. Eliot,Translated and edited by Wang Enzhong. "Eliot's poetry anthology". International Cultural Publishing House, 1989,pp204.

[4] Husserl. "Phenomenol ogi cal concept". Shanghai: Shanghai Translation Publishing House, 1986,pp134.

[5] Husserl. "The crisis of European Sciences and transcendental Phenomenology". Shanghai:Shanghai Translation Publishing House, 1988,pp5

[6] Chen Lingyu. "Subjectivity and human existence". Harbin:Heilongjiang People's Publishing House,2001,pp87.
[7] White. "The Age of Analysis". Beijing:The Commercial Press, 1981,pp208.

[8] Paulo Freire. "The Pedagogy of the Oppressed".Shanghai:East China Normal University Press, 2001,pp25.

[9] F.R.Dallmayr."Twilight of Subjectivity". Shanghai:Shanghai People's Publishing House, 1992.

[10] Liotta. "The postmodern condition". Beijing: Social Science Literature Press. 1999,pp38.

[11] Chen Yousong. "Contemporary Western philosophy". Beijing:Educational Science Publishing Company, 1982,pp28.

[12] Jiagn Xiao. "Study On the Educational Philosophy of American educators". Comparative Education Review, 1988,pp25.

[13] Wittgenstein, Edited by Wright Neiman etc, Translated by Xu Zhiqiang. "Culture and value- Wittgenstein's informal essay". Hangzhou: Zhejiang Literature and Art Publishing House, 2002,pp87.

[14] Marx,Engels."Selected Works".Beijing: Beijing People's Publishing Agency,1995,pp341-342.

[15] Edgar Morin, translated by Chen YiZhuang. "Complexity theory and education". Beijing : Peking University Press,2004,pp43.

[16] Yang Zhongkai, Liu Yongzhen. "From simplicity to complexity". System dialectics report,2002,pp47. 